\title{
Sue Joseph
}

\section{Secrets and 'eloquent episodes': The power of telling the buried story}

\author{
Journalists do not live in isolation. Their values and techniques are part of \\ their \\ culture's larger fabric. \\ Thomas Goldstein (1985: 256)
}

\begin{abstract}
There is often a moment or moments during an interview where a subject's deeply personal experience intersects with the narrative process; 'an eloquent episode' on which the central significance of an entire story resonates.

Drawing on a sequence of interviews with subjects telling deeply hidden, long held secrets, this paper will examine a series of micro moments within each account, both for their narrative power as well as their fundamental consequence to the narrative or macro process. Many of the buried stories in this paper are of traumatic memory, circulating around sexuality, or sexual and violent secrets. Attendant to this is the ethical management of such moments at the time of interview, as well as their subsequent reduction to written words by the interviewer. Incorporating a reflective practice into the text in combination with the undertaking of an ethical practice is an attempt to increase the power of the story. By focusing on 'the eloquent episode' or micro moment, and expanding its bounds, it is the intention of this paper to highlight it as a literary device that reinforces the power of the telling of the story, authenticating not just the voice of the primary storyteller but the narrative.
\end{abstract}

Keywords: narrative, secrets, ethics, eflective practice

Truth, lodged in our most secret nature, demands only to surface; that if it fails to do so, this is because a constraint holds it in place, the violence of a power weighs it down, and it can only finally be articulated at the price of a kind of liberation

- Michel Foucault (1976: 60)

\section{Introduction}

Telling stories is one way people construct meaning, and other people take meaning, from their lives. Much has been written about personal interpretation and memory (by the primary storyteller), and journalistic interpretation and rerepresentation (by the secondary storyteller). But reading about other people is 
a way we can know ourselves - stories resonant across time and borders, through space, language and the differing cultural lenses of each primary storyteller, telling journalists their stories, and the journalists then retelling them as secondary storytellers to the public.

Narrative inquiry as a social science methodology of qualitative research is used to academically frame such journalism/literary journalism practice-led research. Narrative inquiry is academically founded on the hypothesis that we come to comprehend and give meaning to our lives through told stories, necessitating both a story teller and an audience. It is imperative that these stories are not merely collected uncritically but contextualised as remembered personal understandings deriving some meaning. As such, journalism practiceled research academics then play a tandem role as dual narrator, or secondary storyteller.

However the practices of narrative inquiry and journalism/literary journalism practice-led research deviate when it comes to gathering data - or stories - in the field. Whereas narrative inquiry, deriving from within a university, insists on anonymity and uniformity, journalism research as a professional practice bound by ethical codes of conduct and framed by a public right to know or public interest test, necessarily does not. It is of a more organic nature, responding to the moment of each interview. And in terms of handling subjects retelling traumatic events in their lives, often the imperative becomes a form of advocacy journalism where breaking through the silence and telling secrets gives a sense of release and further meaning for the interviewee or primary storyteller. In the case of a journalism practice-led researcher working from within the academy, injecting strands of reflective practice into the final narrative is a means of making more academically rigorous the professional process of their story gathering and retelling.

Having said that, there is a nexus between the main aims of journalism and narrative inquiry - to render people's stories on the page, so we as a society, can understand. Ted Conover talks about a 'literal truth of non-fiction' (in Boynton 2005: 28). Walter Lippmann likens the press to the beam of a searchlight 'bringing one episode and then another out of darkness into vision' (in Cote \& Simpson 2006: 100).

And as sociologist Molly Andrews writes:

I am convinced that if I can listen carefully enough, there is much to learn from every story that one might gather. For society really is comprised of human lives, and if we can begin to understand the framework that lends meaning to these lives, then we have taken the important first step to being able to access the wider framework of meaning that is the binding agent of a culture. (Andrews 2007: 491)

Applying Andrews' position to subjects of trauma choosing to retell their stories, she would seem to be suggesting that we can learn about anomalous societal behaviours, as well as dominant ones. And there is one technique, common to both practices of narrative inquiry and journalism - listening. Australian author Arnold Zable says:

It just takes time ... stories grow from beneath your feet; they grow from the earth. Stories grow from conversations. Stories grow from relationships and it takes a long time to get to know someone. It takes a long time to get to know the depths of their story. (Zable 2011) 
Zable's deference to time is closely aligned to his deference to silence. He talks of the 'eloquent episode' in telling and while he attributes this term to Primo Levi, he says they often:

....arise out of the silence. Part of working with traumatised people is you have to be able to be silent as much as to be talking. Those silences are there and if you won't allow them, the story won't emerge, the real beauty, the terrifying beauty won't emerge. I found that if you listen to someone long enough you will start to hear the eloquent episodes. (Zable 2011)

Maintaining silence is a technique which allows a subject time when retelling their traumatic stories to process their thoughts and retain dignity - it hands back a modicum of control at the moment when they feel least in control. And it allows them to narrate their story in their own way and in their own time.

\section{The 'eloquent episode'}

In Zable's words: 'The eloquent episode is just a moment or a little anecdote that can shift your perception or deepen your understanding of something. It can be terrifying' (Zable 2011). I aim to broaden this description of the 'eloquent episode' when describing interviews with subjects wishing to talk about traumatic events in their lives. I do not believe an eloquent episode need be confined to an anecdote - it can be a heart stopping sentence or two; it can be a held silence. These I call micro moments. The entire narrative - the macro process - may well constellate around these one or two sentences and silences, or micro moments. As Gallant and Vodde explain: '...micro level discourse and self-narratives are the successful deployment and internalization of macro discourses in the form of definitional knowledge and dividing practices' (Gallant \& Vodde 2002: 439). What they mean is that this micro-moment may tell us more about the subject - the primary storyteller - and experiences relayed, than anything else in the spoken story. Accurately rendering this moment to the page then becomes the responsibility of the secondary story teller or journalist. Appropriating organisational management discourse as a metaphor, it is easy to understand the micro to macro impulse: '...choices, values and beliefs of the individual at the micro-level go to produce the amalgam of group atmospheres and cultures. Cultures, therefore, are the sum of the micro-moments that make and remake those particular cultures in an ongoing basis' (Stokes \& Harris 2012: 599). Adapting this definition, the term 'cultures' becomes the macro moment or narrative where these micro moments accumulate and inform. Or for the purposes of this paper and in a more literary sense, the micro moment becomes the device to help articulate the heart of a subject's self-narrative.

Zable talks of the terror of the 'eloquent episode'. Perhaps this is derived from the personal memory of a repression or violence, read and interpreted by the secondary story teller in the manner in which a subject retells - the tenor of the voice; body language; the silences. These are all signifiers of repressed or fearful experience and cause psychic harm of many differing outcomes. The ethical dilemma here is what to do when it is clear that the subject is dissociating or re-experiencing their traumatic memory during interview. Paying due respect by not interrupting and allowing time for regrouping is paramount, then checking in and offering to halt the interview or take a break, is the only way to respond. If the subject regroups and manages his or her own distress, and wishes to continue, then that also must be respected. 
I have been challenged by examiners in peer reviewing processes of previous work about halting an interview. It has been suggested that I do not really mean it because I had invested too much in the project and the work to get to the point of interview. I want to assert here that halting the interview would be easy - I have always believed the mental health of a subject is far more important than the story. And every difficult interview I conduct only enhances my ability to conduct the next difficult interview, even more ethically and empathetically (Joseph 2011: 25). As Cote and Simpson write:

Better reporting about trauma can help readers and viewers gain empathy for the suffering of victims and enrich everyone's awareness of the powerful role that trauma plays in people's collective lives...if the ultimate benefit is greater awareness of how others suffer from trauma, the publics' renewed capacity to offer collective care and support will be the greatest public benefit. (Cote \& Simpson 2006: 8)

This then becomes a part of the reflective response and I argue, if interwoven in between the primary story teller's narrative, leads to a further authentication of the text. The nexus of micro moment and reflection is the space where this can be most effective. Reflective journalism is growing in rigour as a means to create from the journalistic artifact a separate text, examining process within the subjectivity of the secondary story teller. Melding the two together in the narrative lends itself to a third, more critical and combined reading.

In this paper, I intend to focus on the 'eloquent episode', employing Zable's definition but also extending it more broadly from just an anecdote to incorporate the notion that it can also be a mere one or two sentences within narratives from subjects of trauma; or even silent body language. Drawing on a series of interviews with people choosing to tell their stories of deeply hidden secrets, it is the intention of this paper to highlight this extended 'eloquent episode' - or micro moment - as a literary device reinforcing the power of the telling of a story, authenticating not just the narrative but the voice of the primary storyteller. This paper will also examine how by weaving in the journalist's response (secondary storyteller) to these episodes within the text, be it through dialogue or writing of a silence, the moment can be further strengthened and authenticated, in a literary sense.

\section{Primary storytellers}

In this paper, micro moments or 'eloquent episodes' are selected from six narratives from the text Speaking Secrets, a non-fiction work of literary journalism which explores voicelessness and the media (Joseph 2012). The narratives chosen involve secrets and the telling of these secrets, publicly. Using a micro approach at analysis, this paper is concerning itself with the seminal moments from which each narrative constellates, shoring up and authenticating the macro or fuller narrative.

The six narratives each represent some sort of group - or rather, each subject and story is emblematic of a group. And in each instance, each was silenced or repressed in some way by entrenched institutional norms. By examining these closely, and the context in which they were recorded, I hope to unpack these micro moments as ones that authenticate both the narrative and the voice of the primary story teller, thus creating a space for the potential of an inter-textual connection by the reader. In an attempt at transparency and hopefully, further narrative authentication, I intend to also examine techniques within the text 
employed by the secondary story teller to signpost this with the reader. Holt claims that today, authenticity is seen as a 'social construction'. He says it is in constant 'need of negotiation between the individual who have claims to authenticity and the surrounding world' (Holt 2012: 3). His definition resonates for this paper as it is argued that the device of the micro moment is what indeed lends further veracity and gravitas, hence authenticity, to an individual or primary story teller's narrative. This in turn leads to further credibility for both the primary story-teller and the secondary story-teller, or journalist.

The interview subjects are: Russel Sykes (psychologist son of the late Dr Roberta Sykes,[1] conceived during the pack rape of his mother); Jan RuffO'Herne (WWII survivor from the notorious Japanese Virgin Brothels in Java); Arabella Joseph [2] (Melbourne lawyer who wrote a memoir about the systematic sexual abuse she sustained at the hands of her uncle, published by Pier 9); Dorothy McRae-McMahon (second-in-charge of the Uniting Church of Australia when she announced she was gay); Rachael Wallbank (sexually reassigned lawyer who took on the Commonwealth and won); and Lyn Austin (first Stolen Generation person in Australia to receive victim compensation for sustained abuse).

\section{Russel Sykes}

Russel Sykes is a man of more than 50, father of two and a psychologist. His mother, the late Roberta 'Bobbi' Sykes, was a black activist, author and academic. For thirty years he did not know who his father was - his mother kept the means of his conception a family secret, one she protected deeply until about two decades ago. Shortly after his thirtieth birthday, she wrote about it to Sykes in a letter. They never spoke of it. Not even when his mother wrote her autobiographical trilogy Snake Dreaming, including in the first book Snake Cradle page upon page of the an account of her rape by at least four young white men, watched on by another eighteen. It was a race attack which left her for dead - and pregnant.

But she did not die. She dragged herself to get help, and slowly recovered from the attack in Brisbane, Queensland. She then returned home to Townsville to give birth to her son. When Sykes and I were teeing up to meet, he asked me if I knew what his mother looked like, claiming that if I knew what his mother looked like, I would recognise him. In a way, this simple statement: 'Do you know what my mother looks like?' is a micro moment as Russel Sykes looks nothing like his mother. When I told him I did know what his mother looked like, he said: 'Well, you'll know me, then. Except I have a shaved head.'

I include this exchange in the text and in order to leave room for the reader to examine the inference of his statement, I unpack it in the following paragraph. After we have met, I tell him he looks nothing like his mother but leave a rhetorical question hanging. From the text:

I say it to him as we walk towards my office. He carries a briefcase and wears a woollen skullcap. He simply shrugs. But even my seemingly harmless observation is emotionally fraught. If he doesn't look like his mother, does he resemble his father?

Of course, his father is one of the rapists who attacked his mother, resulting in his conception. 
Another micro moment during the interview, incorporated into the text, is when Sykes describes some of his work as a psychologist - how he counsels young, male sex offenders at a juvenile detention centre on the Central Coast of NSW. He refuses to acknowledge a dark irony to this, despite my questioning alluding to his mother's brutal rape and attack by young, male sex offenders. It is a palpable moment - evocative of the way he seems to have dissociated what happened to his mother and his conception, from his own life.

Further in the interview, Sykes refers to his mother's trilogy: 'I don't go there. I don't read those books. I don't want to. The issue is not something - it makes me very unhappy and I don't know - maybe it would make me angrier or something. I don't know.'

Attendant to this is another moment when I ask about the letter his mother wrote to him, when he first learnt of his conception. He says: 'The letter? I probably read it once and I put that letter - I hid it from myself. It was like I didn't need to read it again.'

Again, I find his simple statement so elucidating that I included my own response into the text, paraphrasing my statements to him but linking it as dialogue, quoting him in response directly: I look at him disbelievingly and ask him if he knows where the letter is now. 'Yeah. I think so. It's hidden.'

But possibly the most haunting eloquent episodes arrive towards the end of the interview. There are two micro moments here, which truly authenticate the complexity of this man's understanding of his own life, intertwined with his mother's. I ask him if he ever thinks about his father. He answers: 'The only way I'd relate to them, is to get them. I would inflict serious harm. That would be a time to kill, wouldn't it?' he asks...'Um, um, I always thought there was a balance of good and evil in the world but yeah, evil can be pretty evil.'

I wrapped the interview up and we walked outside, ostensibly to take the photos but perhaps serving more as an opportunity to take a break. I believe this is the most difficult interview I have ever conducted. Sykes had seemingly relaxed a little by this stage, possibly because the interview was drawing to a close. He was sitting for the photos when suddenly he said: 'It's hard to balance it up with thinking that, if it didn't happen, I wouldn't be here. I prefer it didn't happen and that I wasn't here.'

I remember just staring at him at this stage before asking him: 'Do you really mean you wish you didn't exist?' I kept both sides of the dialogue in the text this time, trying to emulate the suspense I, at least, felt. I also included my incredulity. He answered: 'Yeah, no-one should have that experience. I'd just rather my mum didn't go through all that. I'd rather it didn't - it's not something you can really think of in reality, is it?'

Russel Sykes, son, father and psychologist. I probably completely stepped over the boundary when I suggested that perhaps he needed to seek professional help with processing his mother's story, which was also so intensely and meaningfully, his story. I left this exchange in the text because I felt many readers would be thinking the same thing as me. And this was another evocative micro moment of the text. He answered, almost formally: 'It is an error not to. I know it.'

\section{Jan Ruff-O’Herne}


Jan Ruff-O'Herne is a grandmother, now in her late eighties. As a nineteen year old growing up in Java when the Japanese invaded in 1942 during World War II, she was taken from her Dutch family and placed in the notorious Virgin Brothels. Overnight, she became what the Japanese called, a 'comfort woman'. The euphemism is a translation of the Japanese jugun ianfu which means 'military comfort women'. It refers to the more than two hundred thousand women - about one hundred were Dutch; the rest Asian women - taken by the Japanese military before and during World War II and forced into sexual enslavement at the hands of the military.

There were many eloquent episodes in Ruff-O'Herne's narrative. And many times I was moved by her elegance and calmness while relaying her story. The first micro moment however was when she almost spat out: 'We were Japanese war rape victims.' She repudiates the term 'comfort woman'. She went on to say: 'They regarded us like their rations - just like their right to another packet of cigarettes.'

She speaks of her first night in the brothel, and I attempted to write into the text how methodical she was in her telling. It is difficult to convey emotion when a subject is trying to explain systematically a set of horrifying incidents but it is her matter of fact, step by step telling that is so evocative. I believe her delivery, quietly and calmly, denotes her emotion far more than merely commenting on it. Sitting in her Adelaide living room, she retells the story:

I felt like a hunted animal. I told him, 'I would rather die than give myself to you'. He got out his sword and I said, 'Before you kill me, can I say a prayer?' He had paid a lot of money for that first night, because we were virgins, and I knew when he began to undress as I prayed, that he was not going to kill me he never had the intention of killing me. This Japanese officer was in total control of the situation. I tried to fight him off but he was too strong.

This was an inhuman and brutal rape, the first of hundreds ...

Ruff-O'Herne told her mother, her father, a priest, her soon to be husband Tom Ruff, and the British Embassy in Java of the crimes committed against her. Then she did not speak of it for another fifty years.

At the end of the war, the British were sent into Java to protect the Dutch from the Indonesian independence movement which wanted them out. Tom Ruff was one of those British soldiers and they fell deeply in love. He insisted that RuffO'Herne go straight to the British Embassy and report the crimes. A stark micro moment during the interview which I retained as dialogue in the text was what happened then: 'Yes, we reported the crimes and to this day, I have heard nothing from them.'

But the moment when Ruff-O'Herne remembered the night she was returned to her mother in an internment camp just outside Djakarta was the most haunting. She had cut all her hair off in order to make herself ugly to her captors and as she remembered, it seemed to me she dissociated back to that moment. I tried my best to represent her telling, and the feeling in the room as she told, recording it word for word but then attempting to describe the suspense her telling created in that space, in simple language:

... We didn't need to speak. But I will never forget that wonderful feeling of what a mother means. I lay down on the floor on a mattress that was totally worn out and dirty and smelly with sweat, and I just lay in the hole of her arm. I can 
see it now, with her arm around me and she just stroked my head and we just laid there and I felt this safety to be back in my mother's arms. It was just such an amazing feeling. You know, we just lay there; we never spoke. She never asked any questions.

Jan Ruff-O'Herne closes her eyes tightly and I hold my breath. She transports herself back to that night, to that moment, in her mother's arms. She strokes the air, as her mother stroked her hair, and I can almost see it and smell it. The moment is tangible.

It was the next day Ruff-O'Herne spoke to her mother about the rapes.

It was fifty more years from that day before Ruff-O'Herne felt she could speak about these events again. This was a moment in her life she recalls with calmness and assertion. I wrote into the text how she told me about it, using body language and again, simple language. She points to a chair in her lounge room, next to where I am sitting:

I sat there in that chair and I watched the television and I saw the first South Korean woman speaking like this. A little group of people - they had nothing to lose, no more shame because all their family was dead. Now she was going to tell, and for compensation and an apology, especially an apology from the Japanese government.

And she had this small group of other women around her and I thought, God, I should join those women and speak for them, if they have the courage to speak up.

When Ruff-O'Herne talks of her life since the war and the crimes committed against her, she speaks quietly, and again methodically. This final moment indicates post-traumatic stress disorder, something she has lived with since the end of the war:

The war never ended for me; you live with it for the rest of your life. There is always something that triggers it off, you know even at night. I still have it now when I look through the window and it's getting dark. Even now I sometimes still get the terrible fear running through my body, like electrical wires going through your body, this fear, because when it's getting dark it means getting raped over and over and over again and the fear that worked up, you know, in the house. In the brothel, I could see it getting dark, it just totally overpowers your body. I can't describe it. It's just so terrible that you know it's going to happen.

Encounters with survivors of violent crime create especially ethical arenas where monitoring and watching for cues from the subject is of paramount importance. I felt strongly that I stirred up Ruff-O'Herne in the peace of her Adelaide home and was very aware of the level of traumatic memory our interview precipitated. But she insisted on continuing with the interview, seeing herself as an advocate in the fight against rape as a war crime, and her story as a legacy.

\section{Arabella Joseph}


Arabella Joseph is a lawyer and author of a memoir, retelling the systematic sexual and physical abuse she sustained at the hands of an uncle from the ages of eleven to fifteen in Melbourne, Australia. To this day, Joseph has never spoken the words out loud - has never said what he did to her. She has only ever written it, and even then only once, in her memoir. This is an intensely deep silencing which she calls 'the quiet'. An eloquent episode ironically is not that eloquent as she attempts to explain why she cannot speak about what happened:

I know in my head, in my visions - a feeling and a fear - but it's really hard to put into words. It's so hard to explain in words what it was like. I mean, how do you explain how scared - to say 'I was scared' well, you know, I see a moth and I'm scared. It's just a different kind of scared.

Even now there's just not the words. I don't know, it was just terrifying - especially at first, but then we got used to it. It was just a waiting game. We'd go there and until it happened - we already knew it was going to happen - but until it happened we couldn't relax. We'd just wish it would hurry up and happen and then we could just go and play and be safe. It was that whole waiting for something to happen, when we knew it inevitably would.

Her words here evoke a fear suspense and fear, difficult to imagine. Joseph wrote her memoir in third person throughout, as to write in the first person was too close and made it all too real for her, even ten years later. She explained, far more eloquently this time:

...setting it out in a book, it tells the crimes he committed, and then makes that public. And with that information out there, you're either going to touch more people who need to be warned, the parents who do really watch out for the signs and be careful of who their kids are with. Then there are the people who it is happening to. What you're actually doing is giving them a voice. Potentially you are giving a lot of silenced boys and girls a voice.

Perhaps the bleakest moment of the entire interview was her nine word response to a question. She had once told me that since she broke her silence of her abuse, she thought about the terror her uncle imposed on her every ten minutes of every waking day - and in her dreams too. We did the interview during a lunch by the beach. It was raining and I asked her how many times a day she thinks of it now. She repeated my question, but I kept it in the text, as it seemed to invoke a quietness and a pause: 'How many times a day do I think about it now?' She looks toward the sodden beach. 'It's much better now only about once an hour.'

I found her response quite shocking and finished completely subjectively with: 'It is a desolating moment of the interview'.

\section{Dorothy McRae-McMahon}

Dorothy McRae McMahon was a woman in her sixties when we met. I start the chapter about her with:

I first met the Reverend Dr Dorothy McRae-McMahon in a newspaper clippings file. There she was, splashed across 
centimetre column upon centimetre column of newspapers and magazines: female Uniting Church minister, mother, social justice fighter, grandmother - and lesbian.

Second in charge of the Uniting Church in Australia when she came out to a forum of her peers in 1999, I asked her when she was first aware of her own gayness. She started to answer me with: 'Well, I was fifty when I came out.'

She had completely misunderstood me so I interrupted her: 'No,' I say. 'When did you first really know?'

This was a wonderful micro moment, and generationally, told me so much about the woman sitting in front of me. She said:

Oh, in retrospect, I knew when I was a teenager. I did, but I had no name for it - my generation and the culture in which I moved. I've reached through my consciousness. I can't ever remember hearing the word said back then. I must, I suppose, have known people who had same sex relationships but I can't recall knowing it... You didn't talk about it.

McRae-McMahon was born in Tasmania in 1934, moving with her family three weeks later to Victoria. Born into a Methodist parsonage - her father was a minister - she describes her parents as totally engaged with the church their whole lives. She trained as a pre-school teacher before marrying an engineer named Barrie McMahon in her early twenties, and settled into a fairly conventional '50s' married life.

McRae-McMahon speaks of a haunting that her sexuality would be revealed before she had time to tell the people closest to her. Stalked by neo-Nazi fringe group National Front in Australia McRae-McMahon took over her first and only parish at the Pitt Street Uniting Church in Sydney in 1983. She was to be the parish minister there for the next decade. It was a parish of social justice, attracting outcasts from other Christian parishes - including gay people. But the crusade for social justice came at a cost. For years, McRae-McMahon and her congregation were at the centre of a vicious hate campaign by National Action. It was mainly directed at McRae-McMahon's outspokenness on racism - both anti-Semitic and anti-Aboriginal - and homophobia. From the mid1980s, the church was almost weekly vandalised with glue, ink and sump oil. McRae-McMahon received obscene phone calls - day and night. Even death threats. Bags of vomit and faeces were often left in her letterbox or thrown against her house. And one night, she returned home to the inner west to find a burning effigy in her front yard. All incidents were covered by the metropolitan press. McRae-McMahon came very close to being outed by the neo-Nazi group just as she was coming close to telling her family of her sexuality. She was still married - it was 1987 - to Barrie McMahon, and she recollects at the time he may have known of her sexuality conflict. She says: 'The hardest coming out that I ever did was to my husband and children - especially my husband because I didn't want to hurt them.'

The possibility and threat of her secret spreading without her control or in her own time filled McRae-McMahon with fear. She was a thoughtful and generous interview subject and she delivered considered micro moments. About being outed before she was ready, she said:

It made you just go cold - cold with fear about what could happen, partly because the mode of doing it was so entirely out of my hands and that's one of the things about people who tell your secrets that, if you want to tell secrets to anybody, you 
want to have it in your hands in terms of the way you interpret what's happening for you and the mode in which you give that communication.

McRae-McMahon sees her coming out as an incremental process from personal to public - revealing each moment separately, in her own time and under her own control.

\section{Rachael Wallbank}

Rachael Wallbank famously made legal history in the case of the Commonwealth $v$ Kevin and Jennifer, which began in 1998. Wallbank accepted the case on a pro bono basis but was later paid by the Commonwealth when it became a test case. The scientific aspect of the case was based on the concept of 'brain sex', first recorded in the journal Nature in 1995. The argument was made that some people are born with a brain recognising them as different to their public sex or the sex defined by their chromosomes and genitals. And who better to argue the test case and make legal history than someone who had lived it?

In the past, transsexualism was regarded as a psychological condition or mental illness where the person with transsexualism made a choice, and then underwent the surgery and hormone replacement therapies. Brain sex posits that transsexualism is biological and a natural part of human sexual diversity. Wallbank proved it:

All we're saying is, this isn't psychological, this is biological. And that's proved to be the fact by people like me who get to thirty-eight years of life and against all the self-interest that I could find, and every psychological desire I could find, for my own survival's sake I had to act against my desire in order to survive. And that was to affirm myself as female.

Rachel Wallbank is a lawyer and an author and a daughter - and a father. Born Richard, she knew from a very early age that she was really a little girl, in a body which did not make sense to her. Her intelligence and skill at speaking delivers micro moment after micro moment but perhaps she is most powerful when she talks about her three children.

We were sitting in her living room and her 14-year-old son James was working on his computer in his bedroom. Wallbank became quite emotional and pointed to his bedroom, lowering her voice: 'All I knew was that I had to be female or die. And I nearly killed myself on the path to staying male - for that little boy and his sisters. I wanted to be their father worse than anything.'

Her argument is simple - if she could have avoided 'doing this' to her children, she would have. But she had no choice. It was becoming a life and death situation. She delivered these three micro moments in one or two sentences at a time:

...in the end, I had to accept that if I was going to be around, I could only be around as a female. I remember thinking that I needed to be available for these kids and maybe I won't end up being able to see them, but I'll still be available and I'll be alive, whereas I know I'm going to die if I don't be true to who I am - that's what it felt like.

It was more important to be a whole Rachael to my children 
than it was a dead father image. That was the really powerful moment for me. That's when I decided - and I decided to actually transition.

By the end of that struggle I was at the point where, although my life still looked successful - the 'Harvey Norman' life - I wanted to end it. I was just too far from my truth.

Wallbank lives in her family home in Sydney. One of the things I wanted to write into the text was the synchronicity of this fact - the little boy Richard growing up there, not understanding. And the woman Rachael returning, bringing her own children up there. But she bought a far simpler bent to the notion. She said: 'I think you can go back and redeem, and I think that's what I've done with my childhood here. My experience of being here is an experience of finding the little girl who was never able to be.' And then: 'I knew I was female since five or six.'

Talking about her father is hard. He died in June 1999. He had refused to accept her for two years after her transition: 'This was hard for my dad, really hard, but he knew. I had told him when I was little and he knew. He didn't accept it. Not for a long while.'

She then describes the day of acceptance and becomes overwhelmed with emotion again. I just let her talk, not trying to fill in the silences but let her describe what happened, slowly. Wallbank said:

But then, one day he gave me a gift - a beautiful gift. The gift of acceptance. The gift of his seeing me as a female. You've got to see this in the context of the resistance of the guy, and he said: "I just need to tell you that if your mother was alive she'd be as proud of you as I am, for the daughter you are and for the woman you've become. She'd be glad to see you so happy".

A while earlier I had given him a photograph of me looking as I do now, and he had thrown it back onto the ground. But this day, he had put it up amongst all the other family shots in the lounge room. And he said to me: "They can work it out for themselves".

So he put the picture of the little boy who grew up to be a woman on his living room wall and said to me: "All the pictures are up now".

And then he gave me my mother's engagement ring.

And Wallbank then proudly showed me her hand, with the stunning setting sitting on her finger.

\section{Lyn Austin}

Lyn Austin is a near sixty-year-old member of the Stolen Generation. A mother and an activist, she was taken from her own mother at the age of ten, and fostered by a Christian family in the heart of the Victorian countryside, where she was physically, emotionally and sexually abused: physically and emotionally by the foster mother; sexually by the fourteen year old foster brother.

But it is when speaking about her mother, and her removal, that she echoes generations of Australian Aboriginal people and is at her most evocative. It is a crime from which I believe she is yet to, if ever, recover from. Rather, she has had to learn to live with it. Born at Dimboola in Victoria, the eldest of ten 
children, her mother Daphne Ruby took her aside one day and told her she was going away, to get an education. Austin remembers her mother telling her that she would be coming back. She speaks haltingly, trying to find the right word to tell her story:

I can just sort of remember. I suppose because I was so young I didn't understand what was happening. Austin tries to explain. And, no, I don't think my mother and a lot of people back then knew what was happening. They were put in positions because they didn't have the education or the knowledge back then. I think a lot of people were barely able to sign their names. Yeah, so I don't think Mum sort of knew fully. I don't think, you know, I can never understand. I don't think Mum could ever understand either, I think, you know, what was going on...

Austin's body language was palpably one of distress. She refused to look at me when talking, always fiddling with her coffee mug. But then there were moments when she almost defiantly looked up at me, seemingly in defence of her mother. I wrote it all into the text, surrounding her words, and attempted to re-represent her, word for word. It almost seemed more important in this interview than in any of the others. She said about her mother: 'I think maybe she was pressured, as a lot of families were pressured back then to, ah, you know...'

The last Lyn Austin ever saw of her mother was as she was driven to her foster family home, hundreds of miles away, one day in 1964:

It just happened so quickly, you know, one minute Mum's telling me you're going and then that weekend I was gone. And then there was this lady - I don't know if she was from the education department or welfare or where she was from. She just said we're taking you to this farm where there is other Aboriginal children and, you know, it will be better for you to go there and, you know for your schooling, for your education and health and all that sort of thing.

We went in this old FJ Holden actually. I can remember that, the old black FJ Holden.

Her recollections - her traumatic memory recall of the old FJ Holden particularly - demonstrates a filmic quality which is vivid. Again, Austin looked hard at me:

I can still hear my mother's voice - it was in her voice I could tell, you know, the sadness. You know the anguish, and that. I guess probably because I was the first child, see, I was very close to me mother.

I look back, I was looking out the window, like I was waving and, you know, Mum was crying and I always look back and I can see Mum standing on the roadside with her hands, you know, head in her hands crying.

Lyn Austin was planning a trip to meet her mother again but three weeks before she was due to go, she was given the news that her mother had died of a massive heart attack. Austin was only seventeen. Her mother was thirty-six:

I was devastated, I was, you know. I thought, oh, it was - it was devastating 'cause I thought, you know, I wanted to go back and make up for all the lost years that I'd lost with her over the years and to go back and to be with her. You know, to try and 
make up for the years away from her.

And, today I'm, you know, I still, you know, think, you know, why, why, what happened, why didn't we go back? So ...

I chose in this section to focus on micro moments around Austin's removal and her mother because of their highly evocative nature but there were many others I could have focussed on, not least a letter she received from the late Geoffrey Flatman, QC, the Director of Public Prosecution shortly after the decision not to go to trial was taken, where he assured her that she was believed, despite not meeting the evidentiary requirement to take the foster brother to trial. The power of her story is validated in the resonance with other Stolen Generation members' stories - cumulatively, the authenticity of Austin's narrative lends itself to the veracity of their voices.

\section{Conclusion}

This paper set out to discuss the 'eloquent episode' in narrative inquiry as well as journalistic interviews. Arnold Zable calls them anecdotes that effectively bring a subject's story to life, or a seminal moment that resonates. I have attempted to demonstrate that these 'eloquent episodes' or what I call them, micro moments, can be more than just an anecdote. They can be conveyed in as little as a sentence, maybe two, strung together, uninterrupted. By highlighting some of the micro moments in the text Speaking Secrets, it was my aim to examine their reliability as standalone statements, evocative and haunting enough to carry the weight of the narrative and provide a seminal or pivotal moment from which it constellates.

As American scholar and literary journalist, Norman Sims, writes: 'Literary journalists share a goal of bearing witness' (Sims \& Kramer 1995: 13). Conducting these interviews, as the secondary story teller, I felt like I was witnessing sometimes sacred, sometimes fiery, narratives and recounts. Sometimes, also, I witnessed extraordinary pain in the retelling of these stories, repackaged as traumatic memories. Gathering as many 'eloquent episodes' and micro moments is a method of authenticating the telling of a subject's story, particularly pertinent in long form writing and with traumatic material. Contextualising them within a reflective form of writing by the secondary story teller leads to a greater authentication of both the subject's voice within their narrative, or the macro process.

\section{Notes}

1. Dr Roberta 'Bobbi' Sykes died on November 14, 2010, at the age of 67, after suffering a stroke many years earlier return to text

2. Pseudonym and not related to author of paper return to text

\section{Works cited}

Andrews, M 2007 'Exploring cross-cultural boundaries', in DJ Clandinin (ed) Handbook of narrative inquiry: Mapping a methodology, Sage, Thousand Oaks, CA: 489-511 return to text

Boynton, R 2005 The New New Journalism, Vintage Books, New York return to text 
Cote, W \& R Simpson 2006 Covering Violence, 2nd edn, Columbia University Press, New York return to text

Foucault, M 1976 The History of Sexuality, Vol. 1, An Introduction, Penguin Books, London return to text

Gallant, J \& R Vodde 2002 'Bridging the Gap between Micro and Macro Practice: Large Scale Change and a Unified Model of Narrative-Deconstructive Practice', Journal of Social Work Education 38, 3: 439 return to text

Goldstein, T 1985 The News at Any Cost, How Journalists Compromise their Ethics to Shape the News, Simon and Schuster, New York return to text

Holt, K 2012 'Authentic Journalism? A Critical Discussion about Existential Authenticity in Journalism Ethics', Journal of Mass Media Ethics: Exploring Questions of Media Morality 27, 1: $2-14$ return to text

Joseph, S 2011 'Recounting Traumatic Secrets: Empathy and the Literary Journalist', Journalism Practice 5, 1: 18-33 return to text

Joseph, S 2012 Speaking Secrets, Alto Books, Brisbane return to text

Sims, N \& M Kramer (eds) 1995 Literary Journalism, Ballantine Books, New York return to text

Stokes, P \& P Harris 2012 'Micro-moments, choice and responsibility in sustainable organizational change and transformation: The Janus dialectic', Journal of Organizational Change Management 25, 4: 595-611 return to text

Zable, A 2011 Keynote speech at the 2011 AAWP Conference, Ethical Imaginations: Writing Worlds, Byron Bay, NSW return to text

Dr Sue Joseph has been a journalist for more than thirty years, working in Australia and the UK. She began working as an academic, teaching print journalism at the University of Technology, Sydney in 1997. As Senior Lecturer, she now teaches and supervises into both journalism and creative writing schools, particularly creative non-fiction writing, in both undergraduate and postgraduate programs. Her research interests are around sexuality, secrets and confession, framed by the media; HIV and women; ethics; trauma; supervision and ethics and life writing; and Australian creative non-fiction. Her third book Speaking Secrets (Alto Books) was published this year.

\section{TEXT}

Vol 16 No 2 October 2012

http://www.textjournal.com.au

Editors: Nigel Krauth, Kevin Brophy \& Enza Gandolfo text@textjournal.com.au 